\title{
CDKN2A NM_000077.4:C.442G>A
}

National Cancer Institute

\section{Source}

National Cancer Institute. CDKN2A NM 000077.4:C.442G>A. NCI Thesaurus. Code

C146949.

A nucleotide substitution at position 442 of the coding sequence of the CDKN2A gene where guanine has been mutated to adenine. 